\title{
Role of $14-3-3 \sigma$ in poor prognosis and in radiation and drug resistance of human pancreatic cancers
}

\author{
Zhaomin $\mathrm{Li}^{1 \dagger}$, Zizheng Dong ${ }^{1 \dagger}$, David Myer ${ }^{1}$, Michele Yip-Schneider ${ }^{2,4}$, Jianguo Liu', Ping Cui ${ }^{1}$, C Max Schmidt ${ }^{2,3,4}$, \\ Jian-Ting Zhang ${ }^{1,4^{*}}$
}

\begin{abstract}
Background: Pancreatic cancer is the fourth leading cause of death in the US. Unlike other solid tumors such as testicular cancer which are now curable, more than $90 \%$ of pancreatic cancer patients die due to lack of response to therapy. Recently, the level of 14-3-3 $\sigma$ mRNA was found to be increased in pancreatic cancers and this increased expression may contribute to the failure in treatment of pancreatic cancers. In the present study, we tested this hypothesis.
\end{abstract}

Methods: Western blot analysis was used to determine 14-3-3 $\sigma$ protein level in fresh frozen tissues and was correlated to clinical outcome. A stable cell line expressing 14-3-3 $\sigma$ was established and the effect of 14-3-3 $\sigma$ overexpression on cellular response to radiation and anticancer drugs were tested using SRB assay and clonogenic assays. Cell cycle distribution and apoptosis analyses were performed using propidium iodide staining and PARP cleavage assays.

Results: We found that $14-3-3 \sigma$ protein level was increased significantly in about $71 \%$ (17 of 24) of human pancreatic cancer tissues and that the 14-3-3 $\sigma$ protein level in cancers correlated with lymph node metastasis and poor prognosis. Furthermore, we demonstrated that over-expression of 14-3-3 $\sigma$ in a pancreatic cancer cell line caused resistance to $\gamma$-irradiation as well as anticancer drugs by causing resistance to treatment-induced apoptosis and $\mathrm{G} 2 / \mathrm{M}$ arrest.

Conclusion: The increased level of $14-3-3 \sigma$ protein likely contributes to the poor clinical outcome of human pancreatic cancers by causing resistance to radiation and anticancer drugs. Thus, 14-3-3 $\sigma$ may serve as a prognosis marker predicting survival of pancreatic cancer patients and guide the clinical treatment of these patients.

\section{Background}

$14-3-3 \sigma$ is a member of a highly conserved family of 143-3 proteins that are present in all eukaryotic organisms. There are 7 known human 14-3-3 isotypes $(\beta, \gamma, \varepsilon, \eta, \zeta, \sigma$ and $\tau / \theta)[1-3]$ and they play important roles in many biological activities by binding to and altering the subcellular localization and/or stability of key molecules in various signaling cascades $[4,5] .14-3-3 \sigma$ was originally characterized as a human mammary epithelium marker 1 [6] and

\footnotetext{
* Correspondence: jianzhan@iupui.edu

+ Contributed equally

'Department of Pharmacology and Toxicology, Indiana University School of Medicine, Indianapolis, IN 46202, USA

Full list of author information is available at the end of the article
}

later rediscovered as an important molecule for cell cycle checkpoint regulation $[7,8]$.

Recently, proteomic profiling of a drug-selected breast cancer cell line MCF7/AdVp3000 showed that the expression of 14-3-3 $\sigma$ was up-regulated and its expression correlates with the drug resistance level of a series of drug resistant breast cancer cell lines [9]. Further investigation indicated that the elevated expression of 14-3-3 $\sigma$ causes resistance to anticancer drugs by resisting drug-induced apoptosis and inducing cell cycle arrest for repair of DNA damage $[9,10]$.

Pancreatic cancer is the fourth leading cause of death in the US. Unlike some other cancers such as testicular cancer which are now curable, pancreatic cancer is

C Biomed Central

(c) 2010 Li et al; licensee BioMed Central Ltd. This is an Open Access article distributed under the terms of the Creative Commons Attribution License (http://creativecommons.org/licenses/by/2.0), which permits unrestricted use, distribution, and reproduction in any medium, provided the original work is properly cited. 
incurable and more than $90 \%$ of pancreatic cancer

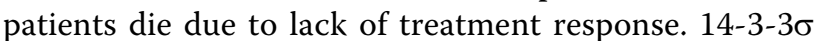
has been reported to be one of a number of genes that have increased expression at its mRNA level in pancreatic cancer tissues as identified by microarray profiling analyses [11-14]. Thus, it is possible that increased 14-3$3 \sigma$ expression may contribute to the failure in treatment of pancreatic cancers. In this study, we tested the hypotheses that $14-3-3 \sigma$ is up-regulated in pancreatic cancers at its protein level and its over-expression may contribute to the failure of treatment of pancreatic cancers by causing resistance to radiation and chemotherapy.

Using fresh-frozen tissues combined with Western blot analysis, we found that $14-3-3 \sigma$ expression was indeed up-regulated in about $71 \%$ of human pancreatic cancer tissues examined and that the 14-3-3 $\sigma$ expression level correlated with lymph node metastasis, consistent with poor prognosis. Furthermore, over-expression of ectopic 14-3-3 $\sigma$ in a pancreatic cancer cell line caused resistance to $\gamma$-irradiation as well as anticancer drugs gemcitabine, mitoxantrone and Adriamycin by causing resistance to treatment-induced apoptosis and G2/M arrest.

\section{Methods}

\section{Human tissues}

All studies involving human subjects have been conducted in strict compliance with and approved by the Institutional Review Board (IRB) of Indiana University School of Medicine and its affiliated hospitals. All patients on this study signed informed written consent for collection of pancreatic tissues at the time of routine operation per the Indiana University Pancreas Lesion Tissue Fluid Bank (IUPLTFB) or IU/Lilly Tissue Bank protocol approved by IRB as described above. Surgical pathology was confirmed in all patients. Pancreatic cancer was staged according to the most current AJCC Guidelines. The matching normal tissues were from the farthest point (at least $20 \mathrm{~mm}$ ) away from lesion (tumor). Tissue specimens were aliquoted and frozen immediately in liquid nitrogen after procurement and stored at $-80^{\circ} \mathrm{C}$.

\section{Sample preparation and Western blot analysis}

Sample preparation and Western blot analysis were performed as previously described [15]. Briefly, the frozen tissues were thawed and homogenized in TNN-SDS buffer $(50 \mathrm{mM}$ Tris- $\mathrm{HCl}$, pH value 7.5, $150 \mathrm{mM} \mathrm{NaCl}, 0.5 \%$ Nonidet P-40, $50 \mathrm{mM} \mathrm{NaF}, 1 \mathrm{mM}$ sodium orthovanadate, $1 \mathrm{mM}$ dithiothreitol, $0.1 \% \mathrm{SDS}$, and $2 \mathrm{mM}$ phenylmethylsulfonyl fluoride) by using pellet pestle (Fisher scientific) and the lysates were clarified by centrifugation $\left(12,000 \mathrm{~g}\right.$ for $30 \mathrm{~min}$ at $\left.4^{\circ} \mathrm{C}\right)$.
The tissue or cell lysates were separated by SDSPAGE and transferred to a PVDF membrane followed by a 2-hr incubation in blocking solution (Tris- or PBSbuffered saline containing $5 \%$ nonfat dried milk and $0.1 \%$ Tween 20) and a 2-hr incubation with monoclonal

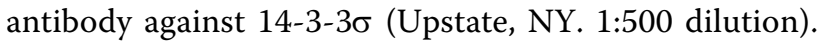
The antibody reaction was detected by horseradish peroxidase-conjugated anti-mouse IgG antibody and visualized using ECL. The relative intensity of the protein on Western blot was measured using AlphaEaseFC Analysis tools (Alpha Innotech).

\section{Cell lines and stable transfection}

BxPc-3 cells (ATCC) were grown in RPMI1640 (Cellgro) supplemented with $10 \%$ fetal bovine serum (Gibco) and $1 \%$ penicillin/streptomycin mixture (BioWhittaker). MiaPaCa-2 cells (ATCC) were maintained in DMEM supplemented with $10 \%$ fetal bovine serum, $2.5 \%$ donor equine serum (HyClone), and 1\% penicillin/streptomycin mixture.

The cDNA of 14-3-3 $\sigma$ was engineered into pcDNA3.1 (+) (Invitrogen). Transfection of this plasmid and its vector control into MiaPaCa-2 cells were performed using Lipofectamine (Invitrogen) and stable clones were selected using $1 \mathrm{mg} / \mathrm{ml} \mathrm{G418} \mathrm{(Invitrogen)} \mathrm{as} \mathrm{previously}$ described $[9,10]$. The stable clones were maintained in

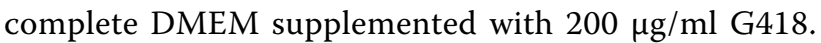
For survival and apoptosis assays, G418 was removed and the cells were maintained in G418-free medium for one week prior to the assays.

Similarly, the stable siRNA knockdown BxPc-3 cells were generated as previously described $[9,10]$. Briefly, BxPc-3 cells were transfected with pSilencer- $\sigma$ (14-3-3 $\sigma$ shRNA cloned into pSilencer 3.1-H1neo vector) or scrambled shRNA construct $[9,10]$ using lipofectamine followed by selection first with $100 \mu \mathrm{g} / \mathrm{ml} \mathrm{G} 418$ for 3 days and cultured for one week in complete medium in the absence of G418. The cells were then selected with $1 \mathrm{mg} / \mathrm{ml} \mathrm{G} 418$ for 2 weeks. Individual clones were tested for $14-3-3 \sigma$ knockdown and positive clones were propagated and maintained in complete RPMI1640 medium.

\section{Cytotoxicity assay}

Cytotoxicity assay was performed as previously described using sulforhodamine B (SRB) colorimetric [16] and clonogenic [17] assays. For SRB assay, cells were seeded in 96-well plate at 5000 cells/well and cultured for 24 hours followed by treatment with anticancer drugs such as Adriamycin, mitoxantrone, gemcitabine or $\gamma$-irradiation and cultured continuously for 3 days. The culture medium was then aspirated, and the cells were fixed and stained by addition of $0.4 \%$ $(\mathrm{w} / \mathrm{v})$ SRB (Sigma) in 1\% acetic acid solution followed 
by incubation at room temperature for 20 minutes. Free SRB was removed by washing cells with $1 \%$ acetic acid 3 times. The bound SRB was then solubilized with $10 \mathrm{mM}$ Tris-base, and the $\mathrm{OD}_{570} \mathrm{~nm}$ was determined using a 96well plate reader (MRX, Dynex Technologies).

For clonogenic assay, cells were seeded in 6-well plate at 100-200 cells/well and cultured for 24 hours followed by irradiation treatment. The cells were then cultured for two weeks before being subjected to fixation and staining with crystal violent $(0.005 \%$ in $20 \%$ methanol) for $30 \mathrm{~min}$. The colonies were counted manually. The radiation enhancement factor was calculated as the ratio of the mean inactivation dose of control cells divided by the mean inactivation dose of 14-3-3 $\sigma$ over-expression and knockdown cells as previously described [18]. A value greater or less than 1 indicates significant radiosensitization or -resistance, respectively.

\section{Cell cycle analysis}

Cell cycle analysis was performed as previously described [10]. Briefly, $5 \times 10^{5}$ cells were seeded in a $10-\mathrm{cm}$ dish and cultured for 24 hours followed by treatments with $\gamma$-irradiation (5 Gy) or mitoxantrone $(10 \mathrm{nM})$ and continuing culture for 24 hours ( $\gamma$-irradiation) or 72 hours (mitoxantrone). The cells were then harvested, washed, and fixed using ethanol followed by staining with propidium iodide and FACS analysis. Cell cycle profiles were determined using CELL Quest and ModiFit programs.

\section{Statistical analysis}

Data analyses were performed with GraphPad Prism (GraphPad Software Inc.) and Excel 2004 (Microsoft, Seattle, WA). Statistical associations between categorical factors were assessed using the Fisher exact test. Survival time was measured from the time of surgery until death or last follow-up (censor date was March 1, 2009). The association of categorical factors with survival was assessed using the Kaplan-Meier method and was analyzed using the log-rank test. Statistical significance was set at $p$ value $<0.05$.

\section{Results}

14-3-3 $\sigma$ protein level is up-regulated in human pancreatic cancers

To determine the status of $14-3-3 \sigma$ expression at its protein level in human pancreatic cancers relative to the corresponding normal tissues, we collected 24 pairs of fresh-frozen normal and cancer pancreatic tissues and determined the protein level of $14-3-3 \sigma$ in these samples using Western blot. The relative 14-3-3 $\sigma$ protein level was then determined. As shown in Figure 1A, 17 of the 24 cases $(70.8 \%)$ show increased $14-3-3 \sigma$ expression in cancers compared to their matching normal pancreatic tissues. This increase is statistically significant (Figure 1B). In many cases, the increase is dramatic with one case (\#114) demonstrating 46-fold increase in cancer compared to normal tissues. Of the 24 cases, 4 (16.7\%) (\#149, \#71, \#7, \#309-03) have decreased 14-3-3б expression in cancer tissues whereas the remaining 3 (12.5\%) (\#56, \#43, and \#303-20) show no observable differences between normal and cancer tissues. These data clearly indicate that the $14-3-3 \sigma$ protein level is significantly increased in the majority of pancreatic cancer tissues compared to their corresponding normal tissues.

\section{Up-regulated 14-3-3 $\sigma$ expression correlates with lymph node metastasis and mortality}

We next examined if the protein level of 14-3-3 $\sigma$ in pancreatic cancers correlates with lymph node metastasis, an indicator of poor prognosis. For this purpose, additional frozen tissues of pancreatic cancers were collected without matching normal tissues. These additional samples are 6-48, 7-39, 8-35, 202-47, 303-11, 310-03, 405-12, 405-58, 503-03, 507-17, 510-65, 512-42, 605-55, 607-10, and 608-12 (see Figure 2). This represents a total of 38 pancreatic cancer tissues of which 17 have lymph node metastasis and 21 do not (Table 1 ). The 14-3-3 $\sigma$ protein level was then determined using Western blot in all these cancer tissues relative to a known pancreatic cancer cell line, $\mathrm{BxPc}-3$, which expresses endogenous 14-3-3 $\sigma$ (Figure 2). The relative expression level of $14-3-3 \sigma$ in all cancer tissues was then correlated with the status of lymph node metastasis. As shown in Table 1, 52.9\% of cancer tissues with lymph node metastasis whereas only $19.0 \%$ of cancer tissues without lymph node metastasis have high 14-3-3 $\sigma$ expression, a statistically significant difference (Table 1). Thus, higher expression level of 14-3-3 $\sigma$ correlates with lymph node metastasis.

Next, a correlation analysis between patient survival

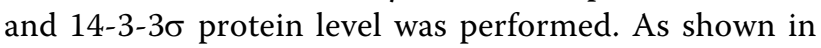
Figure 3, the Kaplan-Meier survival curves demonstrate a trend of higher survival for the low expression group compared to the high expression group $(\mathrm{p}=0.06)$.

\section{Over-expression of $14-3-3 \sigma$ causes resistance to radiation and anticancer drugs}

To determine if $14-3-3 \sigma$ expression is related to treatment resistance in pancreatic cancer, we first tested the treatment response of $\mathrm{MiaPaCa}-2$, which does not express detectable level of 14-3-3 $\sigma$, and BxPc-3, which expresses high levels of endogenous 14-3-3 $\sigma$ (Figure 4A). As shown in Figure 4B, BxPc-3 appears to be more resistant to $\gamma$-irradiation than $\mathrm{MiaPaCa}-2$ cells, with more surviving cells after irradiation treatment. Figure $4 \mathrm{C}$ and $4 \mathrm{D}$ show that BxPc-3 cells are also much more resistant to anticancer drugs Adriamycin and 


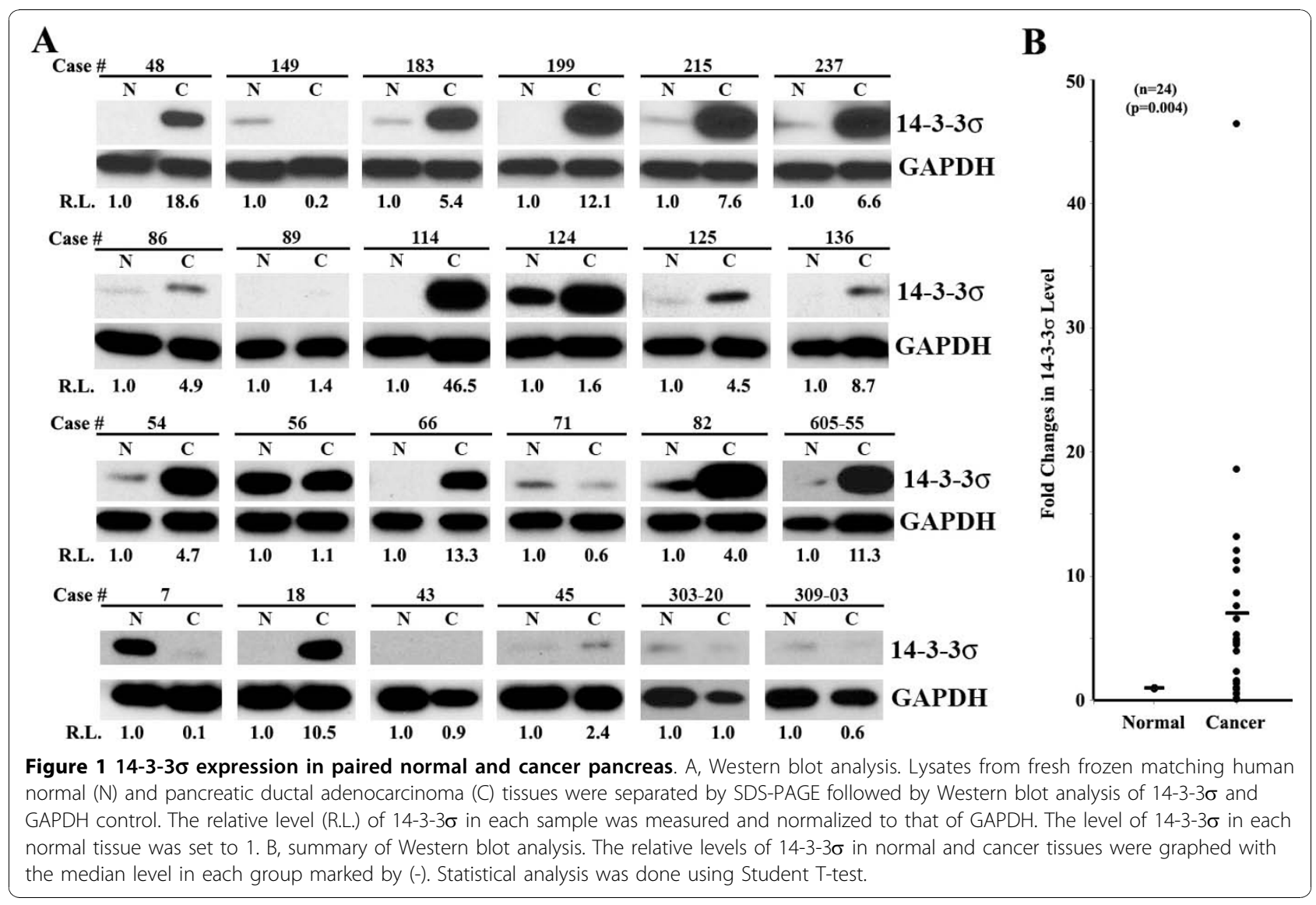

mitoxantrone than MiaPaCa-2 cells. Clearly, the $14-3-3 \sigma$ expression levels in these two pancreatic cancer cell lines positively correlate with their level of radiation and drug resistance.

To determine if 14-3-3 $\sigma$ expression causes drug resistance in pancreatic cancer cells, we established a stable MiaPaCa-2 cell line over-expressing ectopic 14-3-3 $\sigma$ (Figure 5A) and then tested its response to $\gamma$-irradiation first using clonogenic assay. As shown in Figure 5B, the

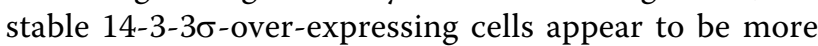
resistant to $\gamma$-irradiation than the vector-transfected (Vec) control cells with a radiation enhancement factor of 0.79 . Thus, over-expression of $14-3-3 \sigma$ in $\mathrm{MiaPaCa}-2$ cells causes a significant increase in resistance to $\gamma$-irradiation.

We next investigated if over-expression of $14-3-3 \sigma$ causes resistance to the anticancer drugs gemcitabine, mitoxantrone, and Adriamycin. As shown in Figure 5C, the stable 14-3-3 $\sigma$-over-expressing cells are significantly more resistant to all three anticancer drugs compared with the stable vector-transfected control clone. Thus, ectopic over-expression of 14-3-3 $\sigma$ causes both radiation and drug resistance in $\mathrm{MiaPaCa}-2$ cells.

To verify the above observations, we created a $14-3-3 \sigma$ knockdown cell clone from BxPc-3 cells (Figure 5D) and tested if knocking down 14-3-3 $\sigma$ would decrease the resistance of $\mathrm{BxPc}-3$ cells to radiation and drug treatment. As shown in Figure 5E and 5F, the stable clone with 14-3-3 $\sigma$ knockdown is significantly less resistant to $\gamma$-irradiation (with a radiation enhancement factor of 1.7), as well as to gemcitabine, Adriamycin, and mitoxantrone than the control cells transfected with scrambled control shRNAs. This finding further supports the conclusion that 14-3-3 $\sigma$ over-expression contributes to treatment resistance in pancreatic cancer cells.

\section{4-3-3 $\sigma$ increases cell cycle arrest upon DNA damage}

Previously, we observed that over-expression of 14-3-3 $\sigma$ increases G2/M arrest upon DNA damage in prostate cancer cells as a mechanism of survival, by allowing more time to repair DNA damage [10]. To determine if the over-expression of 14-3-3 $\sigma$ also causes similar G2/M arrest upon DNA damage in pancreatic cancer cells, we

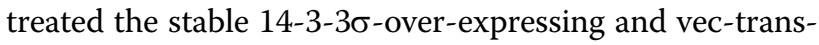
fected control cells with $\gamma$-irradiation or mitoxantrone followed by FACS analysis of cell cycle distribution. As

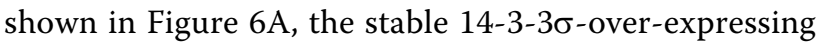
cells clearly have a much higher proportion of cells arrested at $\mathrm{G} 2 / \mathrm{M}$ than the vector-transfected control 


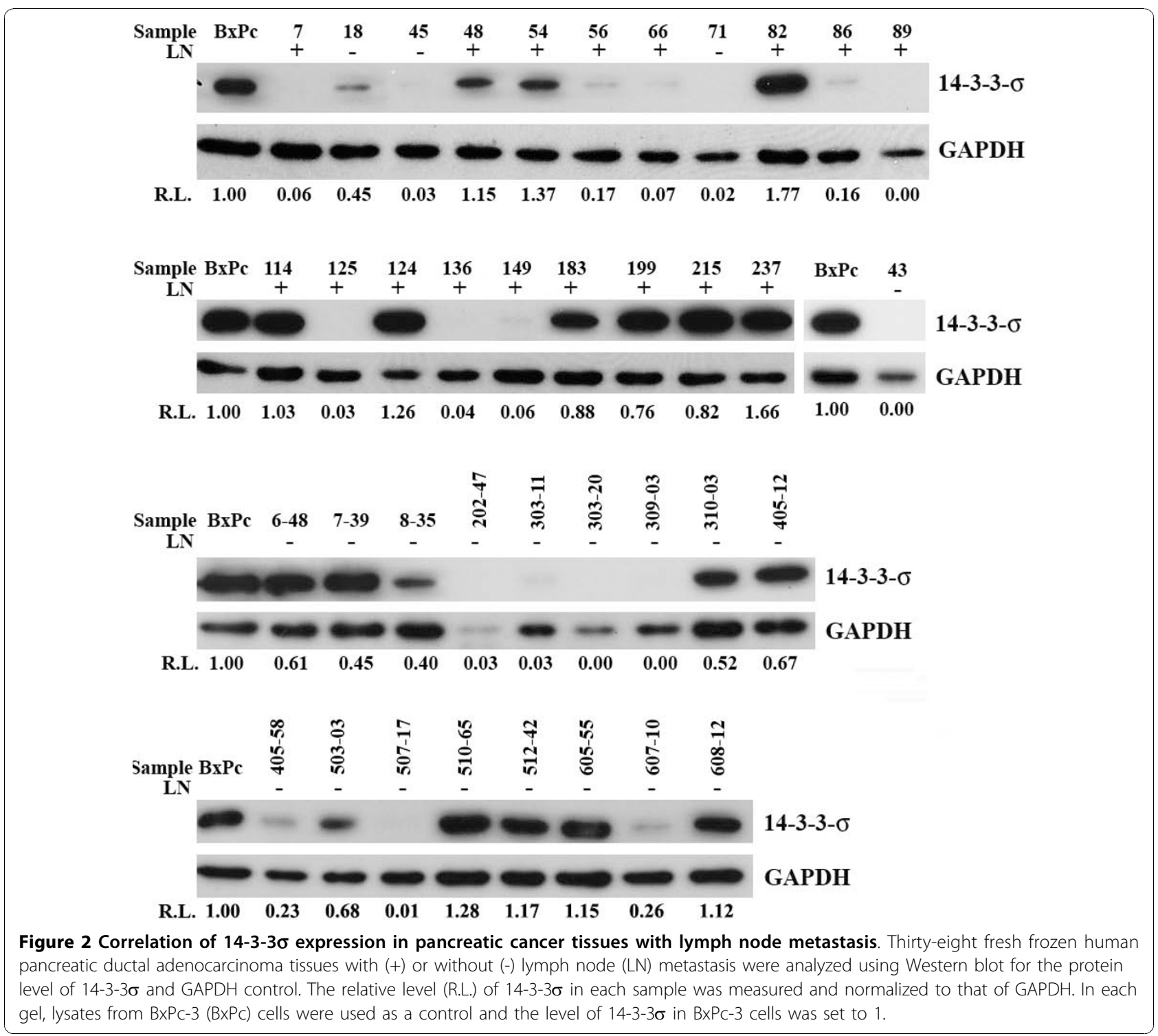

cells following $\gamma$-irradiation or mitoxantrone treatment. Thus, in pancreatic cancer cells $14-3-3 \sigma$ likely provides a protection mechanism by arresting cells at G2/M phase, thereby providing cells an opportunity to repair DNA damage and survive DNA-damaging treatments.

Table 1 Correlation between 14-3-3 $\sigma$ expression and lymph node metastasis

\begin{tabular}{lllll}
\hline Cancer Tissue & \multicolumn{2}{c}{$\mathbf{1 4 - 3 - 3 \sigma}$ expression level } & Total $^{\mathbf{a}}$ & P value $^{\mathbf{b}}$ \\
\cline { 2 - 4 } & High & Low & & \\
\hline Lymph Node $(+)$ & $9(52.9 \%)$ & $8(47.1 \%)$ & 17 & 0.04 \\
Lymph Node $(-)$ & $4(19.0 \%)$ & $17(81.0 \%)$ & 21 & \\
Total & 13 & 25 & 38 & \\
\hline
\end{tabular}

${ }^{\mathrm{a}}$ The expression level was designated high if the staining intensity is above 0.68 and low if equal to or below 0.68 in a post hoc analysis.

${ }^{\mathrm{b}}$ Two-sided Fisher's exact test was used.
14-3-30 over-expression causes resistance to treatmentinduced apoptosis

We next examined if the increased resistance of the stable 14-3-3б-over-expressing cells was also due to inhibition of treatment-induced apoptosis. For this purpose,

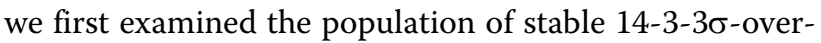
expressing and vector-transfected control cells at the subG1 phase following $\gamma$-irradiation. As shown in Figure

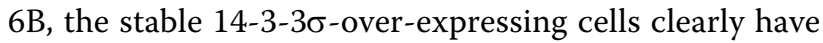
much fewer cells at the subG1 phase compared with the vector-transfected control cells following $\gamma$-irradiation.

We next examined the cleavage of PARP, a target substrate of activated caspases, following treatment with $\gamma$ irradiation or with the anticancer drug mitoxantrone. As shown in Figure $6 \mathrm{C}$, the cleaved $85-\mathrm{kDa}$ fragment of PARP is produced only in the control vector-transfected 


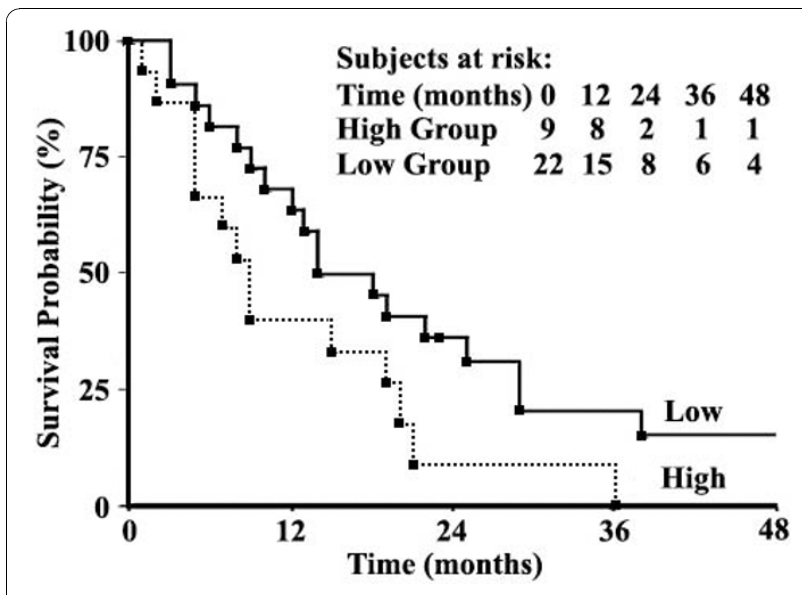

Figure 3 Correlation of $14-3-3 \sigma$ expression in pancreatic cancer tissues with patient survival. Using Kaplan-Meier analysis, the high 14-3-3 $\sigma$ expression group has a trend of lower survival rate than the low expression group ( $p=0.06$, Log-Rank test).

cells following $\gamma$-irradiation. Production of the $85-\mathrm{kDa}$ fragment by $\gamma$-irradiation is apparently inhibited by

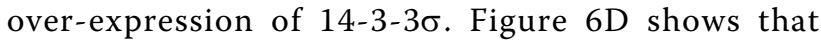
mitoxantrone-induced production of the $85-\mathrm{kDa}$ fragment of PARP is also inhibited by $14-3-3 \sigma$ over-

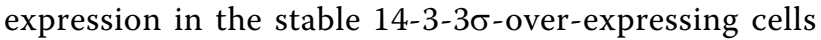
compared with the vector-transfected control. Together, these findings suggest that over-expression of 14-3-3 $\sigma$ in pancreatic cancer cells likely causes resistance to DNA-damage induced apoptosis and, thus, resistance to radiation and drug treatments.

\section{Discussion}

In this study, we demonstrated that the $14-3-3 \sigma$ protein level was increased in a majority of pancreatic cancer tissues studied ( $71 \%)$ compared to their corresponding normal tissues and that the $14-3-3 \sigma$ protein level correlated with lymph node metastasis and patient survival. We also showed that the increased expression of 14-3-36 correlated with poor cellular response to $\gamma$-irradiation and anticancer drugs and that stable over-expression of ectopic $14-3-3 \sigma$ in a human pancreatic cancer cell line, MiaPaCa-2, significantly increased its resistance level to $\gamma$-irradiation as well as anticancer drugs in part by causing resistance to the apoptosis induced by the treatments and by arresting cells in G2/M phase.

It has been reported that 14-3-3 $\sigma$ expression is lost or decreased in human cancers of breast [19,20], liver [21], vulva [22], mouth [23], as well as neuroendocrine tumors

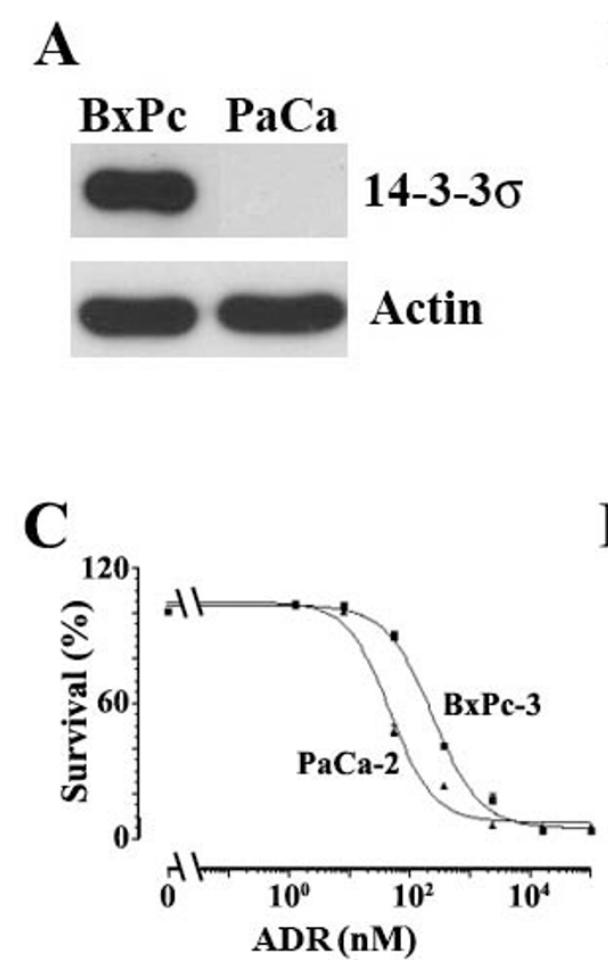

B

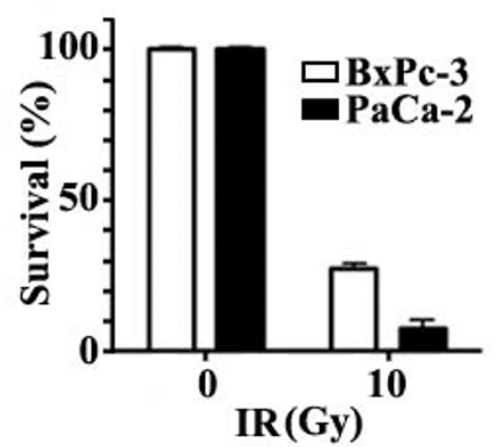

D

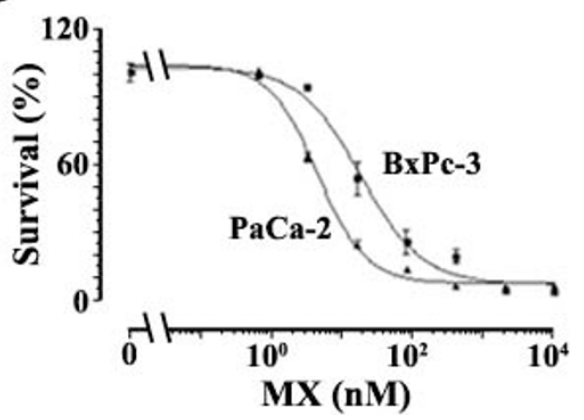

Figure 4 Relationship between 14-3-3 $\sigma$ expression and drug resistance of pancreatic cancer cell lines. A, Expression level of 14-3-3 $\sigma$ in BxPc-3 and MiaPaCa-2 cells. Lysates from BxPc-3 or MiaPaCa-2 cells were prepared for Western blot analyses of 14-3-3 $\sigma$ and actin as a loading control. B, C, and D, Correlation of 14-3-3 $\sigma$ expression and treatment resistance. The effect of $\gamma$-irradiation (B) and anticancer drugs Adriamycin (C) and mitoxantrone (D) on the survival of BxPc-3 and MiaPaCa-2 cells was determined using SRB assay. The survival following treatments was normalized to the control without irradiation or drug treatment. 


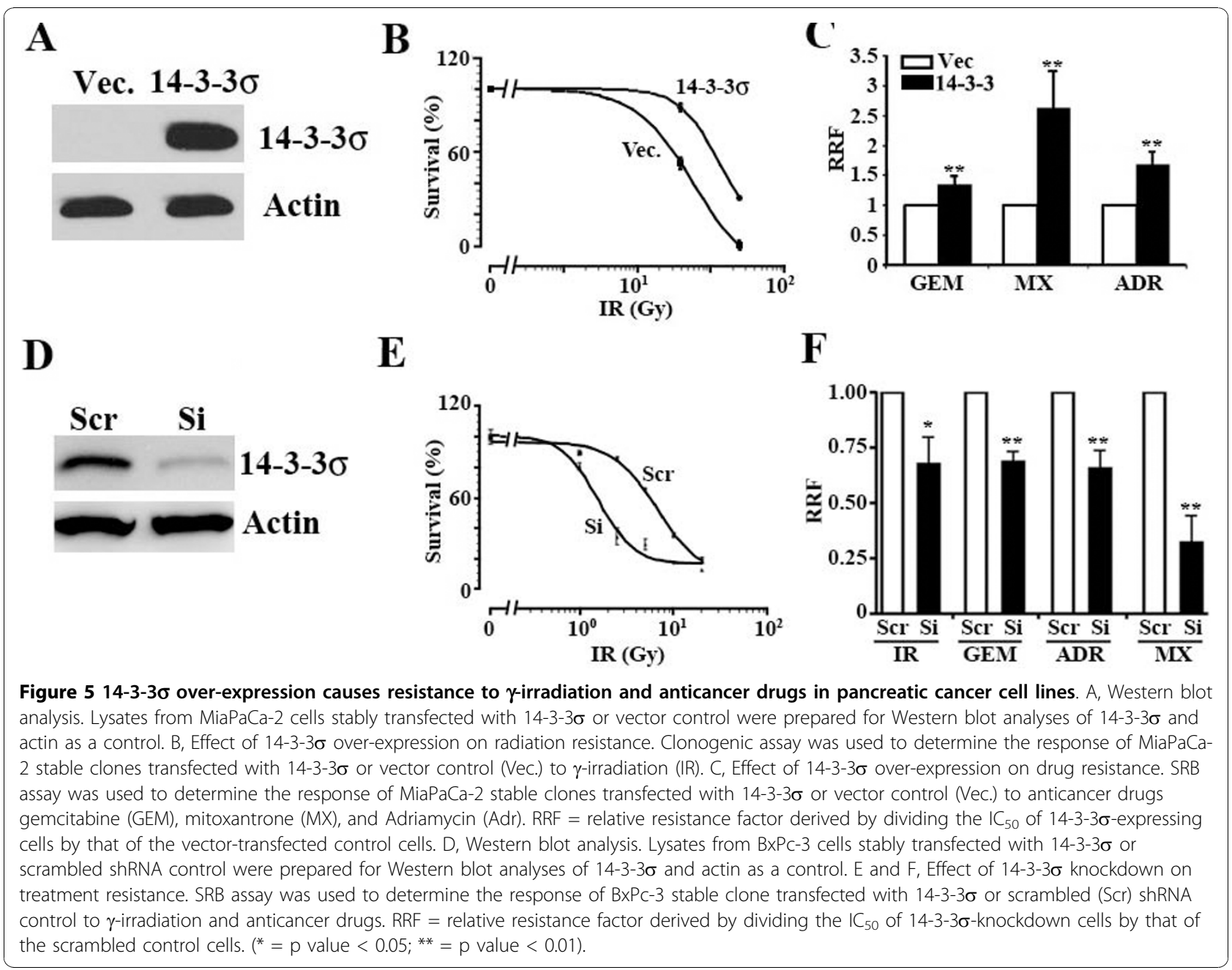

[24], and small and non-small cell lung [25,26] cancers. This decrease is thought to be due to hypermethylation of the CpG islands of the $14-3-3 \sigma$ gene $[19,25,27,28]$.

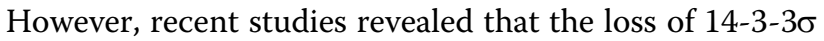
expression in breast cancers is a sporadic event and that its expression is up-regulated in some breast tumors $[29,30]$. From these later studies, it appears that majority of breast cancer cells with basal/myoepithelial phenotype show 14-3-30 expression whereas some of the breast cancer cells with luminal epithelial cell differentiation show decreased or loss of 14-3-3 $\sigma$ expression. Furthermore, it has also been reported that 14-3-3 $\sigma$ expression is increased in lung cancers [31], and head and neck squamous cell carcinomas [32].

In this study, we demonstrated that $14-3-3 \sigma$ protein was increased significantly in the majority (17 of 24 ) of paired fresh-frozen pancreatic cancer tissues examined. Previously, it has also been observed that $14-3-3 \sigma$ is one of the genes with increased expression at the mRNA level in pancreatic cancer tissues using microarray profiling or real time PCR $[11-13,33]$. In the study by Friess et al. [11], a microarray analysis of 5600 human genes in 8 human pancreatic ductal adenocarcinomas and 8 normal tissues showed that $14-3-3 \sigma$ is one of 120 genes that had increased expression at the mRNA level in cancer compared to normal tissues. Similarly, Iacobuzio-Donahue et al. [13] reported that $14-3-3 \sigma$ is one of the genes with increased expression of mRNA in a cDNA microarray profiling study of 17 infiltrating pancreatic cancer tissues compared with 5 normal pancreatic tissues. Using cell lines and methylation specific PCR analysis it was found

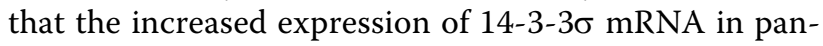
creatic cancer cells may be due to hypomethylation of its promoter region. This later observation is interesting since $14-3-3 \sigma$ in other cancers such as breast cancer is likely to be hypermethylated, resulting in silencing of its expression. Again in a third study, Logsdon et al. [12] used microarray analysis of 10 pancreatic cancer and 5 normal tissues and found 14-3-3 $\sigma$ among 188 genes that had increased mRNA expression in pancreatic cancer 


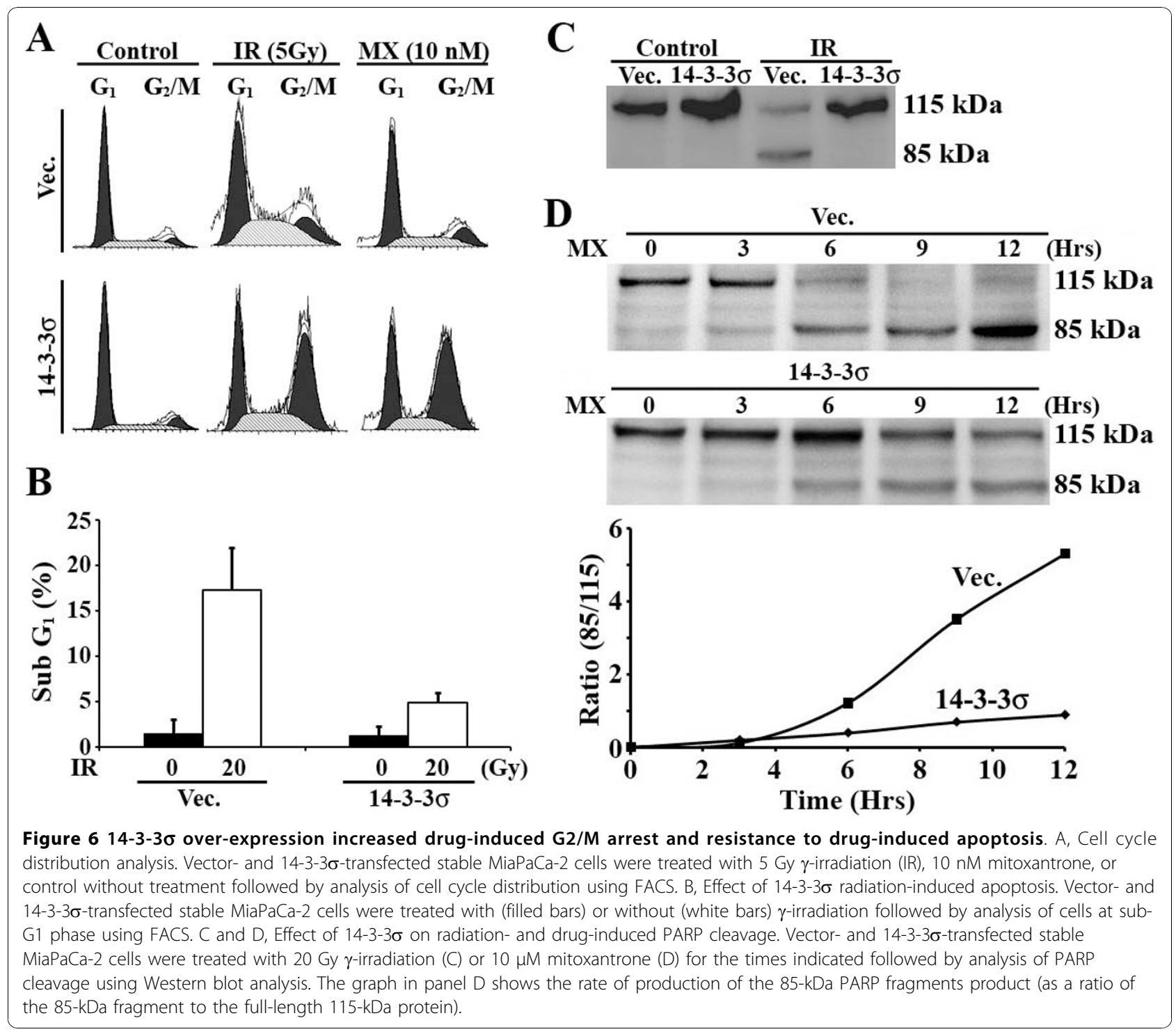

tissues. Using laser capture dissection and real time PCR, Neupane and Korc [33] compared the mRNA levels of all seven 14-3-3 genes in 3 normal and 5 pancreatic ductal adenocarcinoma tissues and found that $14-3-3 \sigma$ is the only gene that has significantly higher expression in cancer tissues. However, all the above studies evaluated the expression of $14-3-3 \sigma$ at its mRNA level. Since the mRNA level does not always predict the protein level, we performed the current study to determine $14-3-3 \sigma$ protein expression in pancreatic cancers and found that the $14-3-3 \sigma$ protein level is indeed significantly increased in pancreatic cancers. This observation is consistent with a previous study by Hustinx et al. [34]. Taken together, these studies clearly show that $14-3-3 \sigma$ expression is increased at both its mRNA and protein levels in pancreatic cancer tissues and the increase may be due to decreased methylation of its promoter.
The finding that the 14-3-3 $\sigma$ protein level is increased in pancreatic cancers is interesting considering that increased 14-3-3 $\sigma$ expression has been shown to cause drug resistance in breast and prostate cancer cell lines $[9,10]$. Indeed, we showed that the increased 14-3-3 $\sigma$ expression in pancreatic cancers appears to correlate with lymph node metastasis, a marker of poor prognosis, and poor survival in a post hoc analysis. Furthermore, over-expression of ectopic 14-3-3 $\sigma$ in a pancreatic cancer cell line, MiaPaCa-2, caused resistance to anticancer drugs as well as to $\gamma$-irradiation while knocking down its expression in BxPc-3 cells reduced the resistance. Thus, the increased 14-3-3 $\sigma$ expression in pancreatic cancer cells may contribute to the failure in the treatment of human pancreatic cancers. Clearly, a more extensive prospective study with more patient samples is needed to further warrant this conclusion. 
Recently, it has also been found that patients with breast carcinomas (both luminal or basal/myoepithelial phenotypes) that have higher cytoplasmic staining of $14-3-3 \sigma$ also have shorter survival compared with patients whose tumors have lower $14-3-3 \sigma$ staining [30]. In estrogen receptor positive tumors, the relationship between 14-3$3 \sigma$ and poor prognosis is even more significant. This later finding is interesting because it has been shown previously that estrogen regulates the stability of $14-3-3 \sigma$ by affecting its proteosome-mediated degradation [35]. In another study of cyclin B1 expression in breast carcinoma, Suzuki et al. also showed that the expression of cyclin B1 and 14$3-3 \sigma$ have a positive correlation and predict a poor prognosis [36]. In a third study, it was suggested that 14-3-3o expression is an independent prognostic marker for poor survival of colorectal cancer patients [37]. In prostate can-

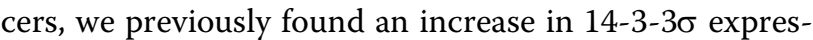
sion as tumor progresses [38]. Adenocarcinomas with high Gleason scores (>7) had significantly higher staining intensities and higher percentages of 14-3-3 $\sigma$ immunoreactive cells than adenocarcinomas with low scores $(<7)$. Adenocarcinomas with lymph node metastases had higher percentages of 14-3-3 $\sigma$ expression compared with adenocarcinomas without lymph node metastases. Thus, over-expression of $14-3-3 \sigma$ may cause resistance to therapies in various cancers. However, it is noteworthy that opposite observations have also been made in endometrial cancer [39], head and neck cancer [40], NSCLC [41], and nasopharyngeal carcinoma [42] where it was found that the absence or low expression level of $14-3-3 \sigma$ predicts poor survival. The reason for the difference between these cancers is currently unknown.

Several popular anticancer drugs used for cancer therapy such as mitoxantrone and Adriamycin are topo II inhibitors which exert their anti-neoplastic effects in susceptible cells by inducing apoptosis, mainly through their ability to induce DNA double-strand breaks. Similarly, $\gamma$-irradiation also causes apoptosis via inducing double strand DNA breaks. However, radiation has also been suggested to induce cell death via mitotic catastrophe. In response to a DNA double-strand break, cancer cells undergo apoptosis or go into cell cycle arrest for repair of DNA which prevents replication of damaged DNA or aberrant mitosis which leads to mitotic catastrophe and apoptosis, thereby, attenuating the toxic effect of the treatments. 14-3-3 $\sigma$ has been shown to be essential for maintaining G2, G1, S cell cycle arrest following DNA damage by interacting with and negatively regulating cyclin dependent kinase $\mathrm{Cdc} 2$, CDK2 and CDK4, which are responsible for cell cycle progression, and prevent mitotic catastrophe and apoptosis $[8,10,43]$. Cells without $14-3-3 \sigma$ are unable to arrest their cell cycle progression and will undergo mitotic catastrophe and apoptosis following DNA damage [43]. Furthermore, 14-3-3 $\sigma$ interacts and negatively regulates Bax and possibly $\mathrm{BAD}$, two pro-apoptotic proteins that regulate the release of mitochondria apoptogenic factors [44]. Thus, increased 14-3-3 $\sigma$ expression in pancreatic cancer cells likely causes resistance to DNA damage-induced cell death.

Gemcitabine, a commonly used drug for pancreatic cancer treatment, does not cause DNA double strand breaks. However, incorporation of gemcitabine into DNA also causes damage to DNA by generating premature termination of DNA replication. The observation that over-expression of ectopic 14-3-3 $\sigma$ increases while knocking down its expression reduces resistance to gemcitabine, suggests that $14-3-3 \sigma$ may also play a role in regulating repair of premature terminations.

\section{Conclusion}

$14-3-3 \sigma$ expression is clearly up-regulated in the majority of pancreatic cancers and it may play an important role in pancreatic cancer cell response to drug and radiation treatments and, thus, likely contributes to the failure in treatment of pancreatic cancers. 14-3-3 $\sigma$ may serve as a prognosis marker predicting survival of pancreatic cancer patients and help physician make critical treatment decisions. Future studies targeting 14-3-3 $\sigma$ for development of chemosensitizers may help better treat pancreatic cancers in combinational therapy.

\section{Author details}

Department of Pharmacology and Toxicology, Indiana University School of Medicine, Indianapolis, IN 46202, USA. ²Department of Surgery, Indiana University School of Medicine, Indianapolis, IN 46202, USA. ${ }^{3}$ Department of Biochemistry \& Molecular Biology, Indiana University School of Medicine, Indianapolis, IN 46202, USA. ${ }^{4}$ IU Simon Cancer Center, Indiana University School of Medicine, Indianapolis, IN 46202, USA.

\section{Authors' contributions}

ZL performed studies of cell lines. ZD performed studies with human tissues. DM, MYS, JL, and PC participated in the studies with either cell lines and/or human tissues. CMS participated in design and coordination of studies with human tissues. JTZ conceived of the study, participated in its design and coordination and drafted the manuscript. All authors read and approved the final manuscript.

\section{Competing interests}

The authors declare that they have no competing interests.

Received: 22 June 2010 Accepted: 1 November 2010 Published: 1 November 2010

\section{References}

1. Fu H, Subramanian RR, Masters SC: 14-3-3 proteins: structure, function and regulation. Annu Rev Pharmacol Toxicol 2000, 40:617-647.

2. Berg D, Holzmann C, Riess O: 14-3-3 proteins in the nervous system. Nat Rev Neurosci 2003, 4(9):752-762

3. Li Z, Liu J-Y, Zhang J-T: 14-3-30, the double-edged sword of human cancers. American Journal of Translational Research 2009, 1(4):326-340.

4. Muslin AJ, Xing $\mathrm{H}: 14-3-3$ proteins: regulation of subcellular localization by molecular interference. Cell Signal 2000, 12(11-12):703-709. 
5. van Hemert MJ, Steensma HY, van Heusden GP: 14-3-3 proteins: key regulators of cell division, signalling and apoptosis. Bioessays 2001, 23(10):936-946.

6. Prasad GL, Valverius EM, McDuffie E, Cooper $\mathrm{HL}$ : Complementary DNA cloning of a novel epithelial cell marker protein, HME1, that may be down-regulated in neoplastic mammary cells. Cell Growth Differ 1992, 3(8):507-513.

7. Hermeking H, Lengauer C, Polyak K, He TC, Zhang L, Thiagalingam S, Kinzler KW, Vogelstein B: 14-3-3 sigma is a p53-regulated inhibitor of G2/ M progression. Mol Cell 1997, 1(1):3-11.

8. Laronga C, Yang HY, Neal C, Lee MH: Association of the cyclin-dependent kinases and 14-3-3 sigma negatively regulates cell cycle progression. J Biol Chem 2000, 275(30):23106-23112.

9. Liu Y, Liu H, Han B, Zhang JT: Identification of 14-3-3sigma as a contributor to drug resistance in human breast cancer cells using functional proteomic analysis. Cancer Res 2006, 66(6):3248-3255.

10. Han B, Xie H, Chen Q, Zhang JT: Sensitizing hormone-refractory prostate cancer cells to drug treatment by targeting 14-3-3sigma. Mol Cancer Ther 2006, 5(4):903-912.

11. Friess H, Ding J, Kleeff J, Fenkell L, Rosinski JA, Guweidhi A, ReidhaarOlson JF, Korc M, Hammer J, Buchler MW: Microarray-based identification of differentially expressed growth- and metastasis-associated genes in pancreatic cancer. Cell Mol Life Sci 2003, 60(6):1180-1199.

12. Logsdon CD, Simeone DM, Binkley C, Arumugam T, Greenson JK, Giordano TJ, Misek DE, Kuick R, Hanash S: Molecular profiling of pancreatic adenocarcinoma and chronic pancreatitis identifies multiple genes differentially regulated in pancreatic cancer. Cancer Res 2003, 63(10):2649-2657.

13. lacobuzio-Donahue CA, Maitra A, Olsen M, Lowe AW, van Heek NT, Rosty C, Walter K, Sato N, Parker A, Ashfaq R, et al: Exploration of global gene expression patterns in pancreatic adenocarcinoma using CDNA microarrays. Am J Pathol 2003, 162(4):1151-1162.

14. Guweidhi A, Kleeff J, Giese N, Fitori JE, Ketterer K, Giese T, Buchler MW, Korc $M$, Friess H: Enhanced expression of 14-3-3sigma in pancreatic cancer and its role in cell cycle regulation and apoptosis. Carcinogenesis 2004, 25(9):1575-1585.

15. Liu Z, Dong Z, Yang Z, Chen Q, Pan Y, Yang Y, Cui P, Zhang X, Zhang JT: Role of elF3a (elF3 p170) in intestinal cell differentiation and its association with early development. Differentiation 2007, 75(7):652-661.

16. Papazisis KT, Geromichalos GD, Dimitriadis KA, Kortsaris AH: Optimization of the sulforhodamine B colorimetric assay. J Immunol Methods 1997 208(2):151-158.

17. Xu J, Peng H, Chen Q, Liu Y, Dong Z, Zhang JT: Oligomerization domain of the multidrug resistance-associated transporter $A B C G 2$ and its dominant inhibitory activity. Cancer Res 2007, 67(9):4373-4381.

18. Morgan MA, Meirovitz A, Davis MA, Kollar LE, Hassan MC, Lawrence TS: Radiotherapy combined with gemcitabine and oxaliplatin in pancreatic cancer cells. Trans/ Oncol 2008, 1(1):36-43.

19. Ferguson AT, Evron $E$, Umbricht CB, Pandita TK, Chan TA, Hermeking $H$, Marks JR, Lambers AR, Futreal PA, Stampfer MR, et al: High frequency of hypermethylation at the 14-3-3 sigma locus leads to gene silencing in breast cancer. PNAS 2000, 97(11):6049-6054.

20. Vercoutter-Edouart A-S, Lemoine J, Le Bourhis X, Louis H, Boilly B, Nurcombe $\mathrm{V}$, Revillion F, Peyrat JP, Hondermarck $\mathrm{H}$ : Proteomic analysis reveals that 14-3-3sigma Is down-regulated in human breast cancer cells. Cancer Res 2001, 61(1):76-80.

21. Iwata N, Yamamoto H, Sasaki S, Itoh F, Suzuki H, Kikuchi T, Kaneto H, Iku S, Ozeki I, Karino $Y$, et al: Frequent hypermethylation of $\mathrm{CpG}$ islands and loss of expression of the 14-3-3 sigma gene in human hepatocellular carcinoma. Oncogene 2000, 19(46):5298-5302.

22. Gasco M, Sullivan A, Repellin C, Brooks L, Farrell PJ, Tidy JA, Dunne B, Gusterson B, Evans DJ, Crook T: Coincident inactivation of 14-3-3sigma and p16INK4a is an early event in vulval squamous neoplasia. Oncogene 2002, 21(12):1876-1881.

23. Gasco M, Bell AK, Heath V, Sullivan A, Smith P, Hiller L, Yulug I, Numico G, Merlano $M$, Farrell PJ, et al: Epigenetic inactivation of 14-3-3 sigma in oral carcinoma: association with p16(INK4a) silencing and human papillomavirus negativity. Cancer Res 2002, 62(7):2072-2076.

24. Yatabe $Y$, Osada H, Tatematsu Y, Mitsudomi T, Takahashi T: Decreased expression of 14-3-3sigma in neuroendocrine tumors is independent of origin and malignant potential. Oncogene 2002, 21(54):8310-8319.
25. Osada H, Tatematsu Y, Yatabe Y, Nakagawa T, Konishi H, Harano T, Tezel E, Takada M, Takahashi T: Frequent and histological type-specific inactivation of 14-3-3sigma in human lung cancers. Oncogene 2002 21(15):2418-2424.

26. Liu Y, Chen Q, Zhang JT: Tumor suppressor gene 14-3-3sigma is downregulated whereas the proto-oncogene translation elongation factor 1 delta is up-regulated in non-small cell lung cancers as identified by proteomic profiling. J Proteome Res 2004, 3(4):728-735.

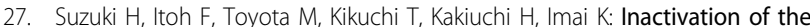
14-3-3sigma Gene Is Associated with 5' CpG Island Hypermethylation in Human Cancers. Cancer Res 2000, 60(16):4353-4357.

28. Umbricht CB, Evron E, Gabrielson E, Ferguson A, Marks J, Sukumar S Hypermethylation of 14-3-3 sigma (stratifin) is an early event in breast cancer. Oncogene 2001, 20(26):3348-3353.

29. Benzinger A, Muster N, Koch HB, Yates JR, Hermeking $H$ : Targeted proteomic analysis of 14-3-3sigma, a p53 effector commonly silenced in cancer. Mol Cell Proteomics, 3 2005, 4(6):785-795.

30. Simpson PT, Gale T, Reis-Filho JS, Jones C, Parry S, Steele D, Cossu A, Budroni M, Palmieri G, Lakhani SR: Distribution and significance of 14-33sigma, a novel myoepithelial marker, in normal, benign, and malignant breast tissue. J Pathol 2004, 202(3):274-285.

31. Nakanishi K, Hashizume S, Kato M, Honjoh T, Setoguchi Y, Yasumoto K: Elevated expression levels of the 14-3-3 family of proteins in lung cancer tissues. Hum Antibodies 1997, 8(4):189-194.

32. Villaret DB, Wang T, Dillon D, Xu J, Sivam D, Cheever MA, Reed SG: Identification of genes overexpressed in head and neck squamous cell carcinoma using a combination of complementary DNA subtraction and microarray analysis. Laryngoscope 2000, 110(3 Pt 1):374-381.

33. Neupane D, Korc M: 14-3-3sigma modulates pancreatic cancer cell survival and invasiveness. Clin Cancer Res 2008, 14(23):7614-7623.

34. Hustinx SR, Fukushima N, Zahurak ML, Riall TS, Maitra A, Brosens L, Cameron JL, Yeo CJ, Offerhaus GJ, Hruban RH, et al: Expression and prognostic significance of 14-3-3sigma and ERM family protein expression in periampullary neoplasms. Cancer Biol Ther 2005, 4(5):596-601.

35. Urano T, Saito T, Tsukui T, Fujita M, Hosoi T, Muramatsu M, Ouchi $Y$, Inoue S: Efp targets 14-3-3 sigma for proteolysis and promotes breast tumour growth. Nature 2002, 417(6891):871-875.

36. Suzuki T, Urano T, Miki Y, Moriya T, Akahira J, Ishida T, Horie K, Inoue S, Sasano $\mathrm{H}$ : Nuclear cyclin B1 in human breast carcinoma as a potent prognostic factor. Cancer Sci 2007, 98(5):644-651.

37. Perathoner A, Pirkebner D, Brandacher G, Spizzo G, Stadlmann S, Obrist P, Margreiter $R$, Amberger A: 14-3-3sigma expression is an independent prognostic parameter for poor survival in colorectal carcinoma patients. Clin Cancer Res 2005, 11(9):3274-3279.

38. Cheng L, Pan CX, Zhang JT, Zhang S, Kinch MS, Li L, Baldridge LA, Wade C, $\mathrm{Hu} \mathrm{Z}$, Koch MO, et al: Loss of 14-3-3sigma in prostate cancer and its precursors. Clin Cancer Res 2004, 10(9):3064-3068.

39. Ito K, Suzuki T, Akahira J, Sakuma M, Saitou S, Okamoto S, Niikura H, Okamura K, Yaegashi N, Sasano H, et al: 14-3-3sigma in endometrial cancer-a possible prognostic marker in early-stage cancer. Clin Cancer Res 2005, 11(20):7384-7391.

40. Erovic BM, Pelzmann M, Grasl M, Pammer J, Kornek G, Brannath W, Selzer E, Thurnher D: Mcl-1, vascular endothelial growth factor-R2, and 14-33sigma expression might predict primary response against radiotherapy and chemotherapy in patients with locally advanced squamous cell carcinomas of the head and neck. Clin Cancer Res 2005, 11(24 Pt 1):8632-8636.

41. Ramirez JL, Rosell R, Taron M, Sanchez-Ronco M, Alberola V, de Las Penas R, Sanchez JM, Moran T, Camps C, Massuti B, et al: 14-3-3sigma methylation in pretreatment serum circulating DNA of cisplatin-plus-gemcitabinetreated advanced non-small-cell lung cancer patients predicts survival: The Spanish Lung Cancer Group. J Clin Oncol 2005, 23(36):9105-9112.

42. Cheng AL, Huang WG, Chen ZC, Peng F, Zhang PF, Li MY, Li F, Li JL, Li C, $\mathrm{Yi}_{\mathrm{H}}$, et al: Identification of Novel Nasopharyngeal Carcinoma Biomarkers by Laser Capture Microdissection and Proteomic Analysis. Clin Cancer Res 2008, 14(2):435-445.

43. Chan TA, Hermeking H, Lengauer C, Kinzler KW, Vogelstein B: 14-3-3Sigma is required to prevent mitotic catastrophe after DNA damage. Nature 1999, 401(6753):616-620. 
44. Samuel T, Weber HO, Rauch P, Verdoodt B, Eppel JT, McShea A, Hermeking H, Funk JO: The G2/M regulator 14-3-3sigma prevents apoptosis through sequestration of Bax. J Biol Chem 2001, 276(48):45201-45206.

\section{Pre-publication history}

The pre-publication history for this paper can be accessed here: http://www.biomedcentral.com/1471-2407/10/598/prepub

doi:10.1186/1471-2407-10-598

Cite this article as: Li et al:: Role of $14-3-3 \sigma$ in poor prognosis and in radiation and drug resistance of human pancreatic cancers. BMC Cancer 2010 10:598.

Submit your next manuscript to BioMed Central and take full advantage of:

- Convenient online submission

- Thorough peer review

- No space constraints or color figure charges

- Immediate publication on acceptance

- Inclusion in PubMed, CAS, Scopus and Google Scholar

- Research which is freely available for redistribution

Submit your manuscript at www.biomedcentral.com/submit 